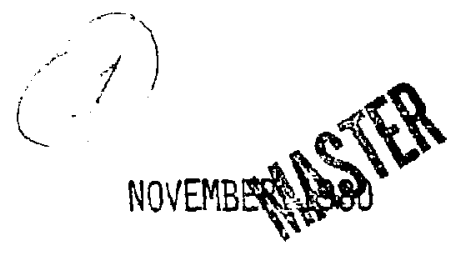

16. 2092

PPPL-1720

uc- $20 \mathrm{~g}$

\title{
DOUBLE LAYERS WITHOUT CURRENT
}

BY

F. W, PERKINS AND $Y, C$, SUN

\section{PLASMA PHYSICS LABORATORY}<smiles>[TeH]</smiles>

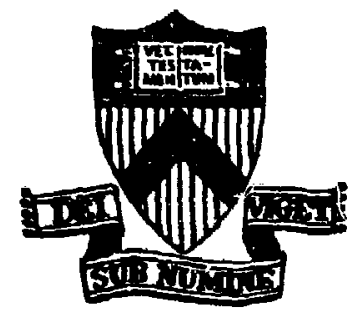

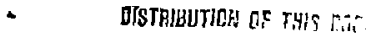

\section{PRINCETON UNIVERSITY PRINCETON, NEW JERSEY}

This work ws supporced by the U.S. Department of Energy ContraC: NO. OE-ACO2-76-CHO 3073. Reproduction, translation, publication, use and disposal, in whole or in part, by or for the United states goverment is permited. 
Double Layers withouc current

F. W. Perkins and Y. C. Sun

Plasma Physics Laboratory, Princeton Universicy

p. 0. Box 451

Princeton, New Jersey 08544

AGS'PRACT

The steady-state solucion of the nonlinear Vlasov-poisson equations is reduced to a nonlinear eigenvalue problem for the case of double-layer (pocential drop) boundary conditions. Solutions with no relative electron-ion drifts are found. The kinetic stability is discussed. Suggestions for creating these states in experinents and compucer simulations are offered.

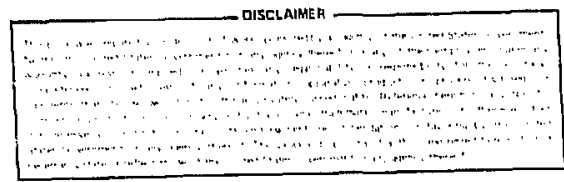


Borh Laboracory exper ments ${ }^{1-3}$ and space-plasma observacions ${ }^{4-6}$ have shown that plasmas can develop scaces which have $\equiv$ narrow, isolated region of rapid porential change surrounded by large regicns of effecrively uniform plasma potencial. Such scates are called double-layers because of the dipolesheet nature of the space change discribution required. Theorecical mode:s1,7-9 of double layers have generally required a relarive electron-ion drift (i.e., a plasma current), but recently computer simulations ${ }^{10}$ and scudies of thermal barrier cells in candem mirror devices ${ }^{1-12}$ have found states with abrupe pocential drops with liccle or no plasma current. Currencless double layers have a parcicular significance for two reasons: (1) Their $+J^{\prime}$ energy dissipation vanishes so that no external energy source is reguired to maincain chem; and (2), in concrast co collisionless shocks, 13 they involve no mass flow and, hence, no supply of streaming plasma is necessary. A currentless solicary wave solucion has recently teen found by Hasegawa and Saco. 14

The goal of this lecter is to find solutions to che Vlasov-Poisson equacions which exhibit the following properties: (1) An isolated region of abrupt porentia: change exists surrounded by regions where the plasma ls quasineutral and the potencial is constant. (2) on the hlgh-density side oE the potential change, the plasma has Maxwellian velocity distributions for both lons and electrons although the respective temperatures may be different. (3) on the Low-density side, the electron velocity distribution remains uaxwellian while the ion distribution is composed of counterstreaming Ion beams. There is no net current. (4) The potencial decreases from the high-riensicy to the low-dengity side.

The key to obtaining these solutions is to recognize that electrostaticaliy trapped ions can exist on the low-density, low-potential 
side. We will regard the density of these trapped ions to be an adjustable paramecer which, cogecher with the magnitude of the pocencial drop, provides us wich two paranecers which are just sufficient to satisfy the two criteria for a double-layer solution: that che low-densicy side be quasineutral and that the cocal charge in the double Layer be zero. Hence, the crapped ion densicy and the potential drop are the two components of a nonlinear, twocomponent eigenvalue problem which determines the double-layer golution.

Our model is that of a one-dimensional viasov-Poisson plasma, and we shall define a nondimensional potential $\downarrow$ related to the convential potentia! by

$$
\psi=-\mathrm{e} \phi / T_{\mathrm{e}},
$$

and choose the $\psi=0$ level to be on the high densicy side. Hence, $\psi$ will be * posicive and monoconically increasing. The sceady-scace vlasov equation is solved by any function of energy. We assume the electron distribution function is everywhere Maxwelizan. our model for the ion distribution Eunctions $\mathrm{f}$ is

$$
\left(\frac{2 \pi T_{i}}{M}\right)^{1 / 2} \frac{f}{n_{0}}-h=\int_{0}^{e^{-\varepsilon}} \quad E>-\Delta .
$$

where

$$
\varepsilon=\left(M v^{2} / 2 T_{i}\right)-\psi \tau, \quad \tau=T_{e} / T_{i} .
$$

The positive parameter $\Delta$ governs the denxigy of electrostatically trapped ions (chose with $\varepsilon<0$ ). The electron and ion densicies can then be expressed as 


$$
n_{e}=n_{0} e^{-1 /,}, n_{i}=n_{0} g(\psi, \Delta) \equiv n_{0} \int_{-\psi \tau}^{\infty} h[\pi(\varepsilon+\psi \tau)]^{-1 / 2} d e \text {, }
$$

and the poisson equation is

$$
\partial^{2} \psi / \partial \xi^{2}=g(\psi, \Delta)-\mathrm{e}^{-\psi} \equiv G(\psi, \Delta),
$$

where $\xi=x / \lambda_{D}$ and $\lambda_{D} \equiv\left(T_{e} / 4 \pi n_{0} e^{2}\right)^{1 / 2}$ is the Debye Iength. Evaluation of the incegral in Eq. (4) leads to

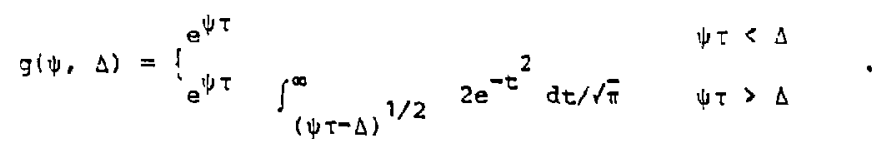

Double layer solutions to Eq. (5) can occur if the net charge density vanishes $-\xi+ \pm \infty$. Our assumption that $\psi \rightarrow 0$ as $\xi+-\infty$ is consiscent wich Lhis condition. This requireme:t, combined with the asymeotic dependence $\psi+\psi_{0}$ as $\xi++\infty$, leads co the equacion

$$
g\left(\psi_{0}, \Delta\right)-e^{-\psi_{0}} \equiv G\left(\psi_{0}, \Delta\right)=0,
$$

as one of the two nonlinear equations relacing the potential change $\psi_{0}$ and $\Delta$.

The electric field must also vanish as $5+ \pm$. Miltiplying En * by $\partial \Psi / \partial \xi$ and incegrating we find

$$
\begin{gathered}
\left(\frac{\partial \psi}{\partial \eta}\right)_{\infty}^{2}-\left(\frac{\partial \psi}{\partial \eta}\right)_{-\infty}^{2}=2 \int_{0}^{\psi_{0}} \mathrm{~d} \psi\left[g(\psi, \Delta]-e^{-\psi}\right] \\
=2 \int_{0}^{\psi_{0}} \mathrm{~d} \psi \mathrm{G}(\psi) \equiv V\left(\psi_{0}, \Delta\right)=0 .
\end{gathered}
$$


Integration by parts simplifies Eg. (8) to read

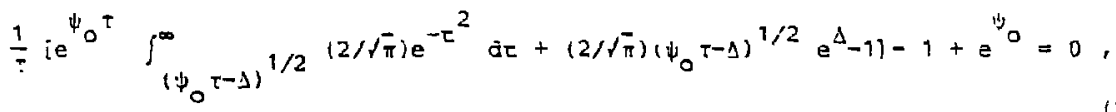

which is the second equation telating $\psi_{0}$ and $\Delta$. Equations (7) and (B) are The nonilinear equations for the cwomcomponent eigenvalue $\left(\psi_{0}, \Delta\right)$. Figure 1 presencs solurions of these equacions for a range of values of che electronromion cemperature ratio $\tau$. We note that in addicion to che pctential change, these double layers have a discinct densicy change $\Delta n / n_{0}=1-e^{-\psi_{0}}$. Equations (7) and (9) coupled with the condition

$$
v(\psi, \Delta)=2 \int_{0}^{\psi} G\left(\psi^{\prime}, \Delta\right) d \psi^{\prime}>0 \quad 0<*<\psi_{0}^{\prime}
$$

represent both necessary and sufficienc condicions for the existence of a loubie-jayer solution. Necessicy follows from the arguments directly preceding Equs. (7) and (B). Sufficiency wiIl be demonstraced by construction. The integral

$$
\int_{\delta \psi_{1}}^{\psi} d \psi^{\prime}\left[v\left(\psi^{\prime}, \Delta\right)\right]^{-1 / 2}=\xi-\xi_{1} \quad \delta \psi_{1}<\psi<\psi_{0}-\delta \psi_{2},
$$

provides the relacion becween $\psi$ and $\xi$ given thac $\psi=\delta \psi$, at $\xi_{5}=\xi_{1}$. The end points muse be creaced specially because the incegral formally diverges chere. The quanticies $\delta \psi_{1}, \delta \psi_{2}$ can be eaken arbitrarily smail, so that a Taylor expansion of $G$ is possible. Hence, near $\psi=0, v=G^{\prime} v^{2}$ and the integral 


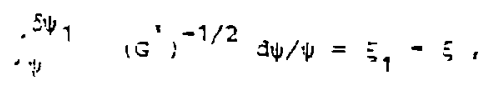

provides the relacion

$$
y=5 \cdot y_{1} \exp \left[\left(G^{\prime}\right)^{1 / 2}\left(5-\xi_{1}\right)\right]
$$

which shows that the solution exponentially decays to zero as $\xi+-\infty$. simizar arguments yiejd an exponentialiy decaying approach to $\psi_{0}$ as $\psi++\infty$. These arguments coupled wich convergent integral Eq. (10) show that, given a $V$ sacisfying Eq. (9) and Eq. (9), a solution can be explicitly constructed. Fiquxe 2 shows represencacive quancitices. Whe noce that if chere were no crapped ions, then it would be impossible co sacisfy Eq. (9).

The two-component eigenvalue is composed of the potential change $\psi_{0}$ plus an addisiona: component (in our case $\Delta$ ) which permits a variation of the plasma distribution function. Thus, in general, a double sayer cannot occur because the plasma will not have the correct vajue of 1 . However, a plasma discribucion function may vary slowly in space (compared to a Debye Lengch) as a result of changes in mirror catio, for example. It follows that these siow spacial variasions pertre a parameter like $\Delta$ to assume che correct value at one point in space which is where the double layer will occus. Hence, the physica: incerprecation of the two-component eigenvalue problem is that one component determines the potential change, the second componenc determines the point where the double layer occurs,

Double layers muse be stable to exist. Clearly, the solution given here is stable to waves in the electron plasma Erequency range because the electron relocity distriburion is everywhere vawellian. on the jow-densiry side, the 
scabilizy sicuacion is that of councerstreaming ion beams.15-17 we shali conEine our actention to electroscacic scability criceria. When che rsdel of a magneric Eield-êree plasma is appropriaze, zaro-frequency modes of the ionacousric branch are most unscable.15 A linear scabilicy analysista yieids scability Eunctions for both paraliel propagating modes $s_{\|}$and obliquely propagacing modes $s_{0}$ at the maximaliy unstable angle ${ }_{M}$ decermined from $\tan \theta_{Y}=(0.66)\left(\psi_{0} \tau-\Delta\right)^{1 / 2}$. The scability cricer a are

$$
s_{0}^{s_{\eta}}=\left\{\begin{array}{l}
1.00 \\
1.29
\end{array}\right\} \tau e^{\psi_{0}+\Delta}\left[\pi\left[\eta_{0} T-\Delta !\right]^{-1 / 2}-\tau-1<0 .\right.
$$

Figure 1c shows that solutions are stable to parailel propagating modes for ai: $t$ and to oblique modes for $\tau<0.8$. We conjecture chat there exist other discribution functions without the abrupt energy cucoff which satisfy che eigenvalue problem and which are scable for larger t values.

If the potential drop occurs along a magnetic field, then we must address the question of scability with respect to electroseatic ion-cyclotron waves. Theory ${ }^{16,17}$ experiment ${ }^{17}$ and space observacions ${ }^{19}$ have shown that inscabilicies occur in this sicuaclon. An analysis shows that purely growing modes are unstable for distrlbution function Eq. (2), but that this conclusion depends on the abrupe energy cutofe. Again, fucura work mast search for diseributions which satisfy Eqs. (7) - (9) and remain stabie co ion-cyclocron modes.

While the dynamics of the formation of a double iayer are outside the scope of this letter, currentless double layers are consiscent with the presence of a negarively-biased transparent gri 1 . This can be seen by excending the definition of $V$ to higher values of $\psi$ 


$$
\begin{aligned}
& -8-
\end{aligned}
$$

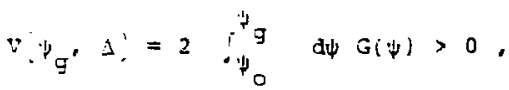

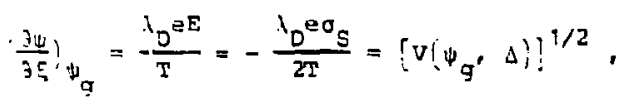

where $\sigma_{S}$ is the (negative) surface charge density of a grid at potentia: ${ }_{g}=-{ }^{\prime} \mathrm{g}_{\mathrm{e}}{ }^{\prime}$. Sence, the incroduction of a negarively charged grid in an ocherwise symmerric plasma device such as a riple plasma device' or mapnetic mirror could lead to the formation of a currentass doubie layer. The compurational simulation analogy is the gradual buildup of $\exists$ Fixed, negarive charge sheer.

In conclusion we have shown that solucion of a cwo-component nonlinear eigenvaiue problem decermines che scruccure of a double layer and spesific resules for a currencless double layer are presenced in Fig. 1 . We argued that the physical information conveyed by the two components is the potentia: drop and the posicion of the double sayer. Definicive statements regarding the kinecic stabilicy with respect to electrostatic ion-cyclotron modes awaic fucure wark.

\section{ACKNONLEDGMENTS}

the are happy to acknowledge stimulating discussions with Drs. P. K. Kaw and H. okuda.

This work was supporced foincly by the U. S. Air Force office oE Scientific Pesenrch under concrace $P R * 80-00656$ wich Pxincecon Universicy and by the U. S. Departmene of Energy Contract No. DE-AC02-76-ch03073. 

Jescribed by a cheory which igtores the effece of a magneric field on che ions because che frequencies and growth races (if unscable) of these modes are weil above the ion-qyrofrequency $\Omega_{i}$ provided the inequalicy $\omega_{p_{i}}^{2}>\Omega_{i}^{2}$ ho:ds. This incoualicy is scrong-y sacisfied in most fusion and space riasmas. Fors:und and shorik 14 have shown chat zero-frequency modes are the most unstabie. Therefore, our scabilicy cricer:on is thac for nargina:iy scabie zeroErequency modes exisc. A quasineutral dispersion rejarion provides a good descriprion of ion-acouscic modes. Serajghrforwara Linear scabiziry ana-ysis yietds the scabi:-cy cricerion

$$
s=\frac{T}{M} ; \quad \frac{d v}{v} \cdot \frac{\partial E}{\partial v},-1=\frac{T}{2}: \frac{d w}{w} \frac{\partial f}{\partial w}-1 \leqq 0,
$$

where

$$
w=v\left(\frac{y}{2 T_{i}}\right)^{1 / 2}, \quad \tau=\frac{T_{e}}{T_{i}},
$$

E is the one-dimensiona: velocity distribution along the direction of the wavevector, an:? the equalicy is the marginal stability condicion. Let $z$ be che difection parallel to the double-layer pocential drop and $\dot{x}$ an orchogona: direceion in which the ion vejocicy distribucion wi: remain Mxweiiian. Let (s, u) denote nondimensiona: velocities in the $(\dot{x}, \hat{z})$ directions respectiveiy and iec the wavevector $\vec{k}$ be in the $\vec{i}$ direction 


$$
\vec{x}=\hat{x}=k n_{x} \hat{x}+n_{z} \hat{z}
$$

x: loubie-iayer mode: chen gives the two-dimensionai velocity distribution

$$
h(s, u)=\vdots_{0}^{(0 / \pi) e^{-\left(s^{2}+u^{2}\right)}} \quad u^{2}>u_{0}^{2}, u^{2}<u_{0}^{2},
$$

where $c$ is a normalizing constanc

$$
e^{-1}=2 / \sqrt{x}: u_{0}^{\infty} e^{-u^{2}} d u
$$

and $u_{0}=\psi_{0}+-a^{1 / 2}$. The one-dimensional velocity distribution $f(w)$ is

$$
\begin{aligned}
f(w) & =i_{-\infty}^{+\infty} \text { ds } \quad i^{\infty}|u|>u_{0} d u(c / \pi) e^{-\left(s^{2}+u^{2}\right)} \delta\left(n_{x} s+n_{z} u-w\right), \\
& \left.=\lim _{0} \frac{c}{n_{x} \pi}\right) \text { du } \exp !-\left(\frac{w-n_{z} u}{n_{x}}\right)^{2}-u^{2} ! .
\end{aligned}
$$

Evaiuaring $\partial f / \partial w$ and using the resulting expression in Eq. (A1), one finds

$$
\begin{aligned}
s+1=-\tau & \int_{-\infty}^{\infty}\left(\frac{c}{\pi n_{x}^{3}}\right) d w \int_{|u|>u_{0}}^{\infty} \exp \left[-\left(\frac{w-n_{z} u^{2}}{n_{x}}\right)-u^{2}\right] d u \\
& +T \int_{-\infty}^{\infty}\left(\frac{c n_{z} u}{w \pi n_{x}^{3}}\right) d w \int_{|u|>u_{0}}^{\infty} d u \exp \left(-\frac{w^{2}}{n_{x}^{2}}-\frac{u^{2}}{n_{x}^{2}}+\frac{2 w n_{z} u}{n_{x}^{2}}\right) .
\end{aligned}
$$


The next step is to incerchange the order or incegracion and perform the w¿ncegracion

$$
s+1=-\frac{\tau}{n_{x}^{2}}+\tau \int_{u_{0}}^{\infty} a u\left(\frac{2 n z c u}{-\frac{2 n}{\pi} n_{x}^{3}}\right) e^{-\left(u^{2} / n^{2}\right)} I\left(\frac{2 n z^{u}}{n_{x}}\right),
$$

where

$$
I(\alpha)=\int_{-\infty}^{\infty} \frac{d n}{\sqrt{\pi} \eta} e^{-n^{2}} \sinh (a \eta)=2 \int_{0}^{\alpha / 2} e^{t^{2}} d t .
$$

The second rerm in Eq. (A9) can be incegrated by pirts to give

$$
s+1=-\tau+\frac{\tau c}{\sqrt{\pi} u_{0}} e^{-u_{0}^{2}} F\left(\frac{n_{z} u_{0}}{n_{x}}\right)
$$

where che Eunction

$$
S(B)=2 B^{2} \quad:_{0}^{1} e^{B^{2}\left(\tau^{2}-1\right)} d \tau=B e^{-B^{2}} I(2 B),
$$

depends only on the orientacion of the wavevector. Two oriencacions are of inceresc: First, parallel propagacion where $B+\infty$ and $E=1$. secondiy, the direccion for which $B=1.51$ where $F$ achieves ics maximu value $F=9.23$. Combining the relacton $c=e^{\psi_{0}^{(:+1)}}$, derived from Eq. (7), wich Eq. (A11), one obcains the stabilicy functions of Eq. (13). 
REFERENCES

1D. Leung. I. Y. Wong, and B. H. Quon, Phys. Fluids 23 :1980) 992.

29. H. Quon and A. Y. Wong, Phys. Rev. Lecr. 37 (1976) 1393.

${ }^{3}$ P. Coakley and N. Hershkowitz, Fhys. Fluids $22(1979) 1171$.

4D. S. Evans, J. Geophys. Res. 79 (1974) 2853.

${ }^{5}$ E. M. Wescocc, M. C. Stenbaek-Nielson, T. J. Hazinan, and T. N. Davis, J. Seophys. Res. 昂 (1975) 4495 .

5S. D. Shawhan, G. -G. Ea:Chammer, and I. D. Block, J. Goophys. Res. 93 (1978) 1049

7.. D. Block, Cosmic El zctrodymanios 3 (1972) 349; F. Carlquist, Cosmic Electrodynamics $\underline{3}(1972) 377$.

${ }^{8}$ G. Knorr and C. K. Geortz, Astrophys. Space Sci. 31 (1974) 209 ; . K. जoertz and G. Joyce, Astrophys. Space Sci. 32 (1975) 165.

'J. R. Kan, L. C. Lee, and S. I. Akasofu, J. Geophys. Fes. B4 (1979) 4305.

${ }^{10} \mathrm{~T}$. Saco and H. Okuda, Ph"s. Pev. Lett. 44 (1980) 740. J. S. Wagner,T. Tajima, J. R. Kan, J. N. Lobouet, S.-I. Fkasofu, and J. M. Dawson, Phys. Rev. Letc. 45 (1980) 303.

${ }^{1} I_{R}$. H. Ohen, "Axial Porencial Profiles in Thermal Barrier Cells," Reporc UCRL-B5535, Lawrence Livermore Iaboratory, Livermore, CA. ${ }^{12} \mathrm{~J}$. Kesner, G. Knorr, and D. R. Nicholson, "Self-Consiscent potencial Variations in Thermal Barriers", Univ. of Iowa Report 80-11 (1980).

${ }^{13} \mathrm{D}$. A. Tidman and N. A. Krall, shock Waves in Coliisionless PLasmasi Wi:ey-Incerscience, New York, 1971$)$ p. 106.

${ }^{4} 4_{A}$. Ha segawa and T. Saco, preprint (1980). 
15D. W. Forslund and C. R. Shonk, Phys. Rev. Lett. 25 (1970) 281.

16F. W. Perkins, Phys. Fluids 19 (1976) 1012.

${ }^{\uparrow} 7_{M}$. Yamada, S. Seiler, H. W. Gendel, and H. Ikezi, Phys. Fluids 20 (1977) 1912.

18 see Appendix.

19P. M. Kintner, M. C. Kelley, R. D. Sharp, A. G. Gielmetti, M. Temerin,C. Cattell, P. F. Mizera, and J. F. Fennell, J. Geophys. Res. B4 (1979) 7201. 


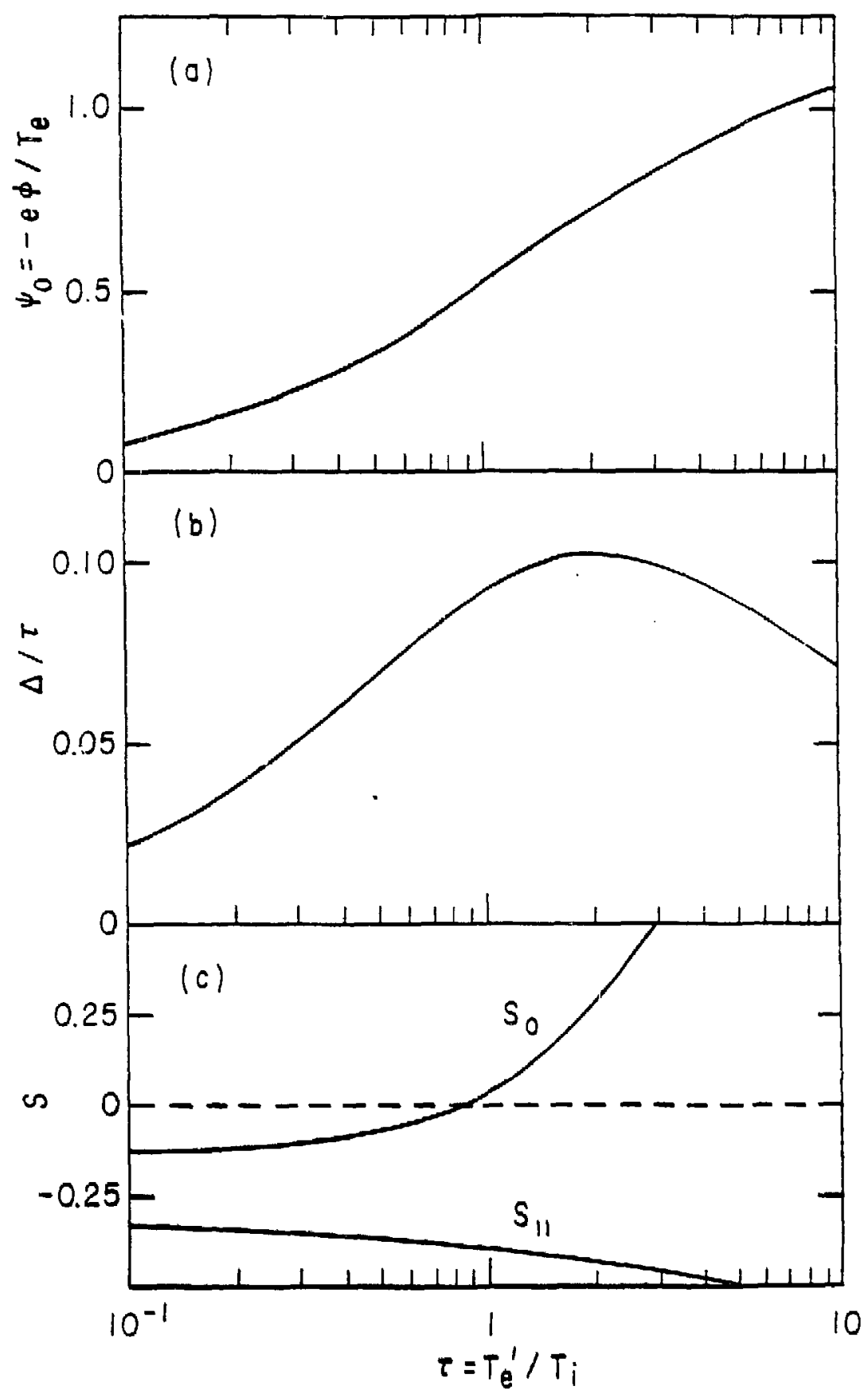

(2PPL-302300)

Eig. $1(a, b)$. Solutions of the nonlinear eigenvalue problem: Note that $\Delta / \tau$ is guite constant. (c). The stabilit $y$ functions $\Xi$ and $\xi_{0}[E q$. (1j)]. s < 0 represents stability. 


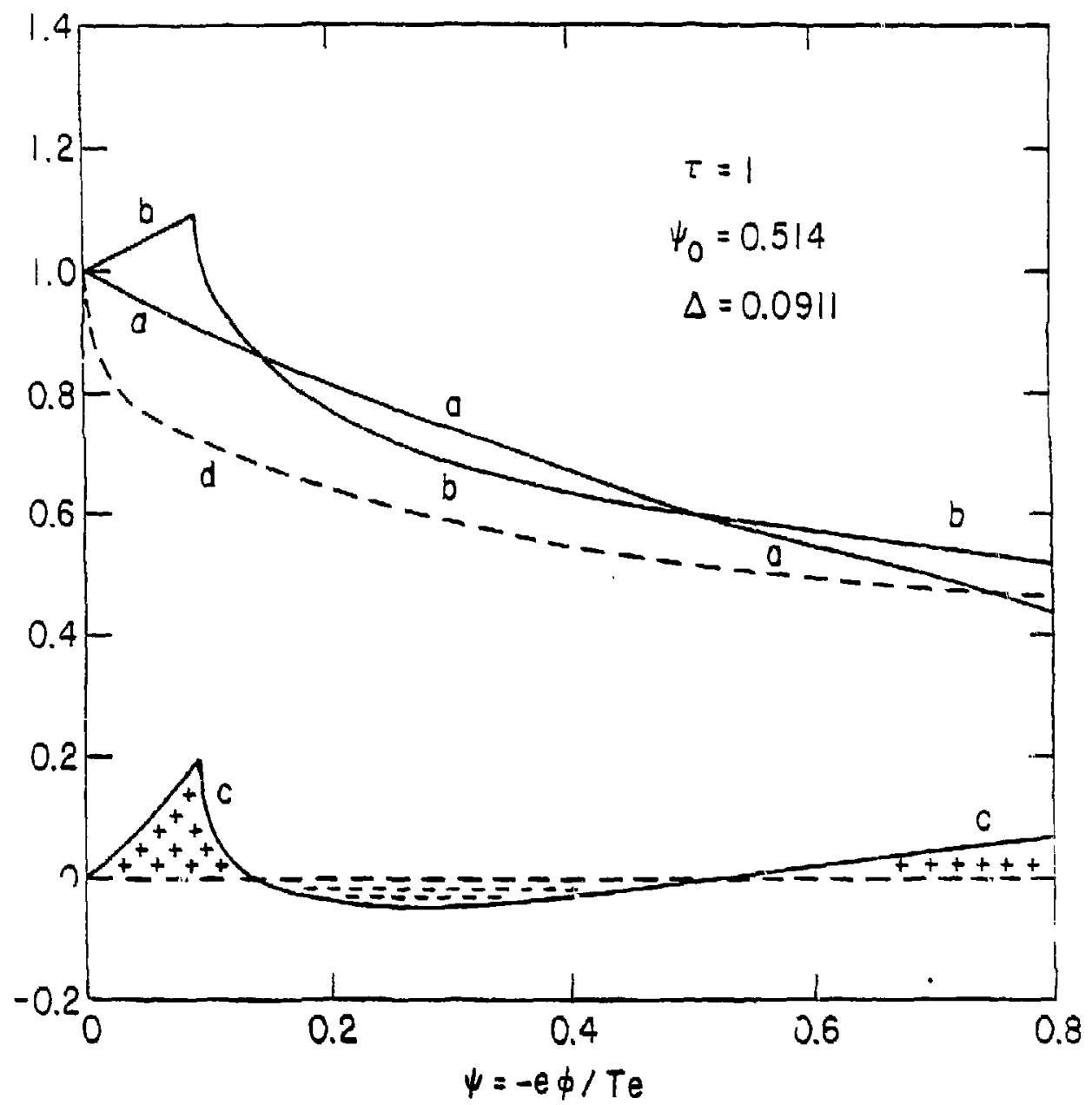

(PPDL-302299)

Fig. 2. Electron and ion densities as a function of potential for $r=I$. Curve $a$ is the electron density $e^{-\psi}$. Curve $b$ is the ion density $g(\psi, 1)$ [Eo. (b)]. Curve $c$ is the difference $G(\psi, \Delta)$ and depicts regions oi positive and neyative charge density. Dashed curved would be the lon densiti it $j-0$. It is evident hat the reguired region of positive charge density rannot exist for $d=0$. 